\title{
Un directorio especializado sobre estudios fílmicos
}

Ricardo Albiñana Bertomeu Universitat Oberta de Catalunya

\section{Palabras clave}

Documentación cinematográfica, Estudios fílmicos, Cinematografía, Bases de datos, Web académica invisible, Web profunda, Directorios temáticos especializados

\section{Resumen}

El propósito general de este trabajo es presentar comunicacioninvisible.net, un directorio temático especializado (DTE) en el campo de los estudios fílmicos. Diseñado específicamente para la investigación, enseñanza y aprendizaje virtual de la comunidad académica y profesional, describe, clasifica y proporciona acceso a la consulta de bases de datos de contenido abierto disponibles en la web, considerando especialmente la calidad de su contenido, accesibilidad y usabilidad. Para la selección adecuada de los contenidos se ha realizado un cuestionario dirigido a docentes, investigadores y profesionales de la comunicación audiovisual y cinematografía. 


\title{
A Subject Gateway for Film Studies
}

\section{Keywords}

Film documentation, Film studies, Cinematography, Databases, Academic invisible Web, Deep Web, Subject gateways

\begin{abstract}
The general aim of this work is to present comunicacioninvisible.net, a subject gateway for film studies designed specifically for research, education and virtual learning within the professional and academic community. It describes, classifies and provides access to open content databases in film studies available on the Web, placing specific emphasis on the quality of their content, accessibility and usability. A survey applied to researchers, teachers and professionals in communication and film studies has been performed for the suitable selection of the databases.
\end{abstract}

\section{Autor}

Ricardo Albiñana-Bertomeu [ralbinana@comunicacioninvisible.net] es licenciado en historia del arte por la Universitat de València, máster en nuevas tendencias y procesos de innovación en comunicación y doctor por la Universitat Jaume I de Castellón. Es documentalista en el Servicio Nacional Informático de la UGT, consultor en la Universitat Oberta de Catalunya y profesor en los másteres online en buscadores y en documentación digital de la Universitat Pompeu Fabra. 


\section{Introducción}

La Web académica invisible (Lewandowski y Mayr, 2006: 531) está compuesta por información almacenada en bases de datos disponible dinámica y públicamente en Internet que no es recuperada por los buscadores convencionales, es decir, no indizada por éstos, y accesible únicamente interrogando sus formularios de búsqueda. Su volumen de crecimiento y calidad es superior a la Web de superficie o Web indexable (Publicly indexable Web), esencialmente porque la mayor parte de las bases de datos son creadas y mantenidas por especialistas en cada materia.

Durante el curso de esta investigación ${ }^{1}$ se ha estudiado este tipo de información y su influencia en el colectivo académico y profesional relacionado con la comunicación audiovisual, cinematografía y documentación audiovisual, creándose como producto final comunicacioninvisible.net, un directorio temático especializado (DTE) en el campo de los estudios filmicos.

Un DTE se puede definir como un servicio centrado en un área del conocimiento que recoge enlaces a sitios web y organiza la información asignando a los recursos digitales una o más categorías o subcategorías mediante un cuadro de clasificación elaborado previamente.

Su elaboración se realiza manualmente por profesionales que seleccionan los recursos siguiendo unas directrices para asegurar su calidad. Su finalidad principal es facilitar la descripción de una manera rápida y eficaz a recursos de calidad para investigadores, personal docente o estudiantes de un nivel académico superior (universitarios, postgraduados, doctorandos), sin ningún ánimo lucrativo, sólo para favorecer la investigación y el incremento de conocimiento.

El propósito principal de comunicacioninvisible.net, es proporcionar la descripción y acceso a la consulta de bases de datos de calidad de contenido abierto en la web relacionadas con este campo. Dirigido especialmente a investigadores, docentes y profesionales, es una base de datos de bases de datos, y por el momento, un servicio único en la web hispanohablante. Se puede acceder al mismo desde la siguiente URL [http://www.comunicacioninvisible.net].

Figura 1. Cabecera y menú del sitio comunicacioninvisible.net

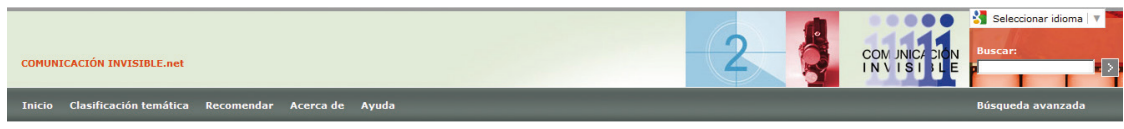

1 El presente trabajo es producto de la investigación realizada por Ricardo Albiñana para la tesis doctoral, La Web académica invisible en el campo de los estudios filmicos, dirigida por Javier Marzal, Catedrático de Comunicación Audiovisual y Publicidad de la Universitat Jaume I y la Dra. Fernanda Peset, Profesora titular del Departamento de Comunicación Audiovisual, Documentación e Historia del Arte de la Universitat Politècnica de València. Ha sido realizado con la ayuda del Proyecto de Investigación Nuevas Tendencias e hibridaciones de los discursos audiovisuales contemporáneos y financiado por la convocatoria del Plan Nacional de I+D+i del Ministerio de Ciencia e Innovación, para el periodo 2008-2011, con código CSO2008-00606/SOCI, bajo la dirección de Javier Marzal. 
En cuanto a los profesionales de la documentación audiovisual, está dirigido tanto a la figura del librarian (López de Solís, 2007: 139), que en el ámbito anglosajón se refiere a la persona que trabaja en un centro de documentación audiovisual y que analiza, clasifica y recupera los documentos que llegan a dicho centro, como al profesional de la documentación en producción cinematográfica o researcher, film-researcher o documentador (Cuadra, 2006: 167), es decir el encargado de documentar una obra, localizar el material audiovisual, sonoro o fotográfico u ocuparse de la gestión de derechos audiovisuales y musicales.

\section{Desarrollo del catálogo de recursos}

\subsection{Planificación y aspectos técnicos}

Para asegurar la consistencia en la selección y mantenimiento de la calidad de la colección, el diseño de comunicacioninvisible.net se ha estructurado en torno a los procesos de planificación, aspectos técnicos y arquitectura de la información propuestos por Lynch y Horton (2008), Tramullas, Garrido, Navarro y Senso (2003) y los criterios de selección de una colección recomendados por el proyecto DESIRE, Information gateways handbook, (Worsfold, 1998). Estos criterios se pueden resumir en un servicio en línea que proporciona el enlace y la descripción a bases de datos web de acceso abierto, cuya autoría ha sido contrastada, las descripciones se han sometido a un proceso de selección realizado manualmente, con unas normas de calidad preestablecidas y cada recurso se ha descrito mediante metadatos, un resumen, unas palabras clave y una clasificación establecida.

Para su desarrollo se ha utilizado CWIS (Collection Workflow Integration System) [https://scout.wisc.edu/Projects/CWIS/], software cedido gratuitamente por la Universidad de Madison, realizándose la traducción y la adecuación de sus plantillas e interfaces al español.

Las razones para su elección han sido:

- Es un programa interoperable y de software libre, que tiene como finalidad específica la creación y mantenimiento de colecciones de datos académicos, educativos o de investigación, ofreciendo mecanismos de introducción, corrección y consulta de datos.

- Sus posibilidades para organizar y compartir colecciones de datos conforme a la normativa de metadatos Dublín Core Metadata Initiative (DCMI) [http://dublincore.org].

- La capacidad de su interfaz de propocionar acceso al contenido a todo tipo de usuarios, independientemente de sus medios técnicos y de sus capacidades físicas, siguiendo la normativa del World Wide Web Consortium (W3C), Web Accessibility Initiative (WAI) [http://www.w3.org/WAI].

- Los años de funcionamiento, desarrollo, mantenimiento, seguimiento del programa y organismos que lo utilizan y apoyan. 


\subsection{Selección de los contenidos}

En cuanto al repertorio de recursos de información, este trabajo se ha centrado en la selección de bases de datos de cobertura nacional e internacional de dominio público, es decir, cuando se realiza sin cargo al usuario o simplemente mediante su identificación.

Para una selección adecuada de las mismas, se ha diseñado y enviado un cuestionario a investigadores, docentes y profesionales de la comunicación audiovisual, cinematografía y documentación audiovisual.

Su aportación más relevante ha sido, por una parte, obtener datos para realizar un análisis global del sector, y por otra, conocer sus necesidades de información, identificar los recursos y fuentes informativas más utilizadas y el grado de satisfacción en la utilización de las mismas en el desarrollo de su trabajo.

El producto pretende demostrar que el investigador no debe limitarse a usar en su trabajo los resultados generados por los motores de búsqueda convencionales y ha servido como base para el diseño y elaboración del DTE. El presente estudio expone que existe una relación significativa entre la experiencia profesional de los investigadores en el campo de los estudios fílmicos y los nuevos medios y formas de comunicación tecnológicamente convergentes a través de Internet, en concreto la dificultad de acceso y consulta a fuentes de información y contenidos audiovisuales y textuales de calidad de libre acceso en la web.

Los principales parámetros considerados para el diseño del cuestionario fueron los siguientes:

- Unidades de análisis: Docentes/investigadores, cuya línea de trabajo fuera la comunicación audiovisual, específicamente el campo de los estudios fílmicos, o apliquen estudios similares, profesionales que consultan de forma habitual dicha temática y especialistas en documentación audiovisual, archiveros, bibliotecarios y documentalistas.

- Dimensiones e indicadores: Capacidades y conocimientos en la recuperación de información y utilización y frecuencia de uso de servicios de información de calidad especializados en el campo de los estudios fílmicos en la web.

- Tipos de preguntas. El cuestionario elaborado estaba compuesto por 27 ítems de diverso tipo agrupados en las siguientes áreas:

- Identificación y datos demográficos de los encuestados.

- Líneas de investigación y necesidades de información.

- Aspectos relacionados con el uso de instrumentos de búsqueda de información específicos en Internet en el campo de los estudios fílmicos. 
Otro aspecto importante del diseño fue decidir el tipo de acceso que tendrían los usuarios al cuestionario. En este caso, para su contestación se utilizó un formulario online, ya que Internet brinda más oportunidades para realizar estudios más eficaces y rápidos que los medios tradicionales, mediante un acceso restringido, (identificación con un usuario y contraseña).

La selección de la población se realizó en entidades educativas, científicas y profesionales, limitándose a instituciones de educación superior y grupos de investigación, identificándose un tamaño poblacional de 100 candidatos (recibiéndose 62 cuestionarios cumplimentados correctamente). En el cuestionario se hizo detallar, mediante preguntas estructuradas y abiertas, la siguiente información:

- Identificación.

- Institución académica o profesional a la que pertenece.

- Años de experiencia.

- Líneas de investigación o desempeño profesional que cursa o ha cursado.

- Utilización de recursos de información en la web.

- Frecuencia y el tipo de acceso a las bases de datos más empleadas con que contaba el investigador.

- Nivel de destreza en la utilización de bases de datos.

- Opiniones acerca del acceso libre a las bases de datos y evaluación de la calidad de recursos de información en el campo de los estudios fílmicos.

El análisis descriptivo de los cuestionarios se realizó desde dos perspectivas:

- Para el análisis de datos cuantitativo y administración se utilizó el paquete estadístico y plataforma web Limesurvey, [http://www.limesurvey.org/]. El sistema utilizado permite exportar dichos datos a otras plataformas estadísticas, así como estudiar las gráficas comparativas de los resultados según los grupos de preguntas definidos.

- El análisis cualitativo de los datos se realizó, debido a la posibilidad de incluir opiniones y sugerencias, mediante un resumen de los comentarios libres más relevantes y reiterados de cada apartado con el fin de agruparlos por áreas de contenido.

Entre los principales resultados obtenidos el $67.27 \%$ de los encuestados reconoció que no había realizado trabajos de investigación donde la única fuente de información fuera Internet, mientras un $30.91 \%$, respondió afirmativamente. De este último grupo, el tipo más común de investigación fue la descriptiva con un $24.52 \%$, siguiéndole con una porcentaje aproximado al $21 \%$ la histórica, la experimental y la exploratoria. 
Sobre las razones por las que consulta Internet como instrumento para la docencia o investigación:

- $\quad$ El $61.20 \%$ reconocían que la consultaba para conocer novedades.

- Un $20.90 \%$ en busca de alguna publicación para su consulta o préstamo.

- El 17.70 \% restante para la obtención de datos primarios como:

- Imágenes y films.

- Datos sobre empresas.

- Datos profesionales sobre autores e investigadores.

- Compra de libros.

- Obtención de artículos.

- Consultas filmográficas.

- Intercambiar conocimientos.

Los aspectos más valorados en la consulta de materiales para la investigación en Internet fueron:

- La búsqueda y recuperación de la información sobre los documentos (bases de datos, catálogos electrónicos).

- La posibilidad de obtener libros, artículos de revistas y/o documentos a texto completo.

- $\quad$ El acceso a material audiovisual completo.

Concerniente al tipo de acceso a la consulta de bases de datos, el 55,74\% lo realiza mediante licencia institucional y el $42 \%$ restante consulta bases de datos acceso gratuito. En total, el $83 \%$ reconocieron útil o muy útil el dominio de las técnicas de búsqueda y evaluación de la información para la investigación y el $85.45 \%$ consideraron la conveniencia de que los recursos accesibles en Internet sean evaluados por profesionales.

El siguiente grupo de preguntas se centró en la facilidad o dificultad para encontrar información útil y de calidad y en la utilización y conocimiento de servicios en Internet para la recuperación de información en el campo específico de los estudios fílmicos. Entre los recursos de información más utilizados fueron las bases de datos de pago proporcionadas por los departamentos, bibliotecas de las universidades u organismos. Entre ellas:

- Film Index International [http://fii.chadwyck.com/home].

- Base de datos de la Federación Internacional de Archivos Fílmicos, [http:// www.fiafnet.org/uk/publications/fdbo.html]. 
- American Film Institute Catalog (AFI) [http://afi.chadwyck.com/home].

- Gaumont-Pathé Archives [http://www.gaumontpathearchives.com/].

Y las siguientes bases de datos de acceso gratuito según el orden en la preferencia de uso:

- Intenet Movie Database (IMDb) [http://www.imdb.com/].

- Datos de películas calificadas del Ministerio de Cultura español [http:// www.mcu.es/cine/CE/BBDDPeliculas/BBDDPeliculas_Index.html].

En el desarrollo de sus investigaciones los encuestados destacan en orden de frecuencia la utilización de los siguientes recursos y materiales:

- Frecuentemente: buscadores, bases de datos de pago o suscripción, catálogos de bibliotecas, editoriales y librerías, publicaciones periódicas electrónicas, repositorios de documentos, portales web, noticias, imágenes y audiovisuales, bibliografías, libros, films y filmografías.

- Algunas veces: diccionarios, enciclopedias, tesauros, estadísticas y audiencias, convocatorias, congresos, novedades, becas y recursos sobre empleo, festivales, premios, eventos y conferencias, archivos, sitios web comerciales/promocionales, información sobre la industria cinematográfica, tesis e investigaciones y críticas de cine.

- Casi nunca: blogs, foros y listas de discusión, páginas personales, directorios de profesionales, normas, información legal y guiones de cine.

El tipo de contenido y las utilidades que ha adoptado el DTE en función de las necesidades detectadas mediante la fase de análisis del cuestionario han sido siguientes:

- Consultar y visualizar films y filmografías clasificados por continentes y países, sitios web monográficos sobre largometrajes determinados, estrenos, cortometrajes, películas en línea, películas en dvd, carteles de películas y tráileres.

- Conocer el lenguaje cinematográfico y el análisis documental de la imagen mediante obras de referencia relacionadas con la cinematografía como diccionarios, glosarios, tesauros y enciclopedias.

- Acceso a fuentes de calidad para preparar materiales de producción, crear ambientaciones y localización de exteriores y documentar y preparar proyectos como informes, dosieres de prensa, perfiles biográficos y entrevistas.

- Acceso a bibliografías, catálogos de bibliotecas, filmotecas, hemerotecas, librerías, editoriales especializadas, archivos fílmicos, directorios de profesionales, empresas y asociaciones, y publicaciones especializadas.

- Trabajos de conservación, recuperación y restauración de films. 
- Legislación y derechos intelectuales, audiovisuales, musicales, editoriales, morales, patrimoniales, entidades de gestión, permisos, licencias y cuestiones jurídicas relacionadas con la imagen e industria cinematográfica.

- Consulta a reseñas o textos completo de guiones cinematográficos y críticas cinematográficas.

- Formación, cursos y estudios relacionados con la comunicación audiovisual y los estudios fílmicos y centros públicos y privados que se ocupan de la enseñanza cinematográfica.

- Festivales, premios, congresos, actos y galardones relacionados.

- Acceso a foros, listas de discusión y blogs.

- Información estadística de la industria cinematográfica y aspectos sobre producción, distribución, exhibición cinematográfica e industria de servicios, profesionales y técnicos.

- Música en el cine, bandas sonoras y compositores.

- Información, imágenes, planos y programación de salas cinematográficas.

- Tesis doctorales, proyectos de investigación e investigaciones defendidas en universidades relacionadas con la técnica, teoría e historia del cine.

- Textos literarios adaptados a la pantalla.

- Bases de datos de aspectos sociológicos, históricos, culturales, ideológicos, sociales, económicos y políticos relacionados con el cine.

\subsection{Clasificación y evaluación de los contenidos}

Los contenidos se ofrecen estructurados para lo que se ha creado un sistema de clasificación específico (ver figura 2) que asegura la consistencia semántica a lo largo de todo el directorio. Para determinar el cuadro de clasificación se han analizado las clasificaciones de la Biblioteca del Congreso (LCC), la Clasificación Decimal Universal (CDU), las utilizadas en directorios temáticos especializados en cinematografía como el Film Links Gateway del British Film Institute, INTUTE, Cine DOCnet de la Universidad Complutense de Madrid y el sistema de clasificación de la Federación Internacional de Archivos Fílmicos (FIAF).

Esto permite orientar al usuario en la obtención de información mediante la navegación por las categorías y una búsqueda más restringida o más amplia para poder localizar registros sobre aspectos relacionados.

El cuadro de clasificación adoptado definitivamente no contiene notación numérica, lo que le somete a la ventaja de futuras adaptaciones y reaccionar más ágilmente absorbiendo nuevas áreas de interés, ya que el programa facilita el movimiento de registros entre clasificaciones. 
Figura 2. Acceso a la clasificación temática del DTE.

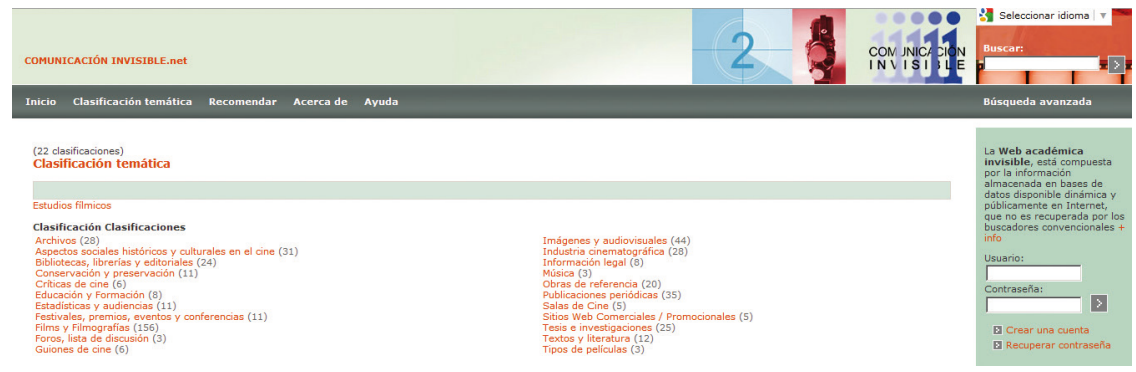

Esta clasificación se complementa con palabras clave o materias. Este sistema, no plantea las limitaciones de la clasificación jerárquica porque recurre a un vocabulario controlado específico, lo que permite una descripción más detallada del contenido de cada base de datos. Para ello, se ha traducido al español el vocabulario realizado por la Federación Internacional de Archivos Fílmicos $(\mathrm{FIAF})^{2}$.

Para decidir la idoneidad de incluir un recurso en el DTE se ha realizado la adaptación del método «Evaluación de bases de datos documentales y motores de búsqueda: parámetros e indicadores», propuesto por Lluís Codina (2001). Una vez evaluadas las bases de datos, se procedió a su descripción mediante una ficha, optándose por una representación básica de origen bibliográfico. Para el contexto que nos ocupa, las características o descriptores utilizados en la descripción de las bases de datos forman parte del conjunto propuesto por la normativa de metadatos Dublín Core Metadata Initiative ${ }^{3}$.

\subsection{Sistemas de búsqueda de los contenidos}

Desde la página principal se accede a las distintas secciones utilizando las opciones que aparecen en la barra de menú (ver figura 1). Su función principal, además de mostrar al usuario los últimos registros introducidos en el sistema o novedades y la sección de noticias o advertencias que desee publicar el administrador, es ofrecer las dos posibilidades de consulta de los registros.

La primera, mediante la navegación o exploración, se accede por la opción Clasificación temática, donde el usuario puede navegar por medio del cuadro de clasificación. La presentación de la información atiende a un nivel de detalle conforme se profundiza en los niveles jerárquicos, al tiempo que ofrece la secuencia que se ha seguido durante el proceso de búsqueda, proporcionando varios niveles antes de acceder al listado de registros.

2 General subject headings for Film Archives [http://www.fiafnet.org/uk/publications/iifp_subjectHeadings.html].

3 Dublín Core Metadata Initiative (DCMI) [http://dublincore.org]. 
La segunda, mediante la recuperación de información, a través de dos interfaces de consulta para la formulación de expresiones de búsqueda. Una de nivel básico, mediante la simple introducción de términos. En el caso de no obtener los resultados esperados, o simplemente si se desea concretar más los criterios de búsqueda, existe la opción de refinar la consulta haciendo uso de la Búsqueda Avanzada, donde se pueden realizar consultas en mayor detalle utilizando los operadores booleanos, AND, OR y NOT, en los campos específicos título, autor, editor, clasificación, materia y descripción.

La presentación de los resultados (ver figura 3), está estructurada en dos niveles. Uno más sencillo o listado general, con la presentación breve de datos para evitar la sobrecarga cognitiva, donde aparece primeramente el título, una parte de la descripción (190 caracteres) y la URL de la dirección de la base de datos, y otro con la posibilidad de ver el registro completo. En ella se recoge el enlace, procurando que apunte directamente a la pantalla de búsqueda, la entidad o persona responsable de su creación, su clasificación, materias, una breve descripción de su contenido, incluyendo naturaleza de los datos, opciones de búsqueda, idioma, volumen de información, tipo de recurso, fecha de su última actualización y la posibilidad de realizar comentarios y las utilidades de valorar los registros y guardar las búsquedas realizadas si el usuario se ha registrado en el DTE.

\section{Figura 3. Descripción de una base de datos.}

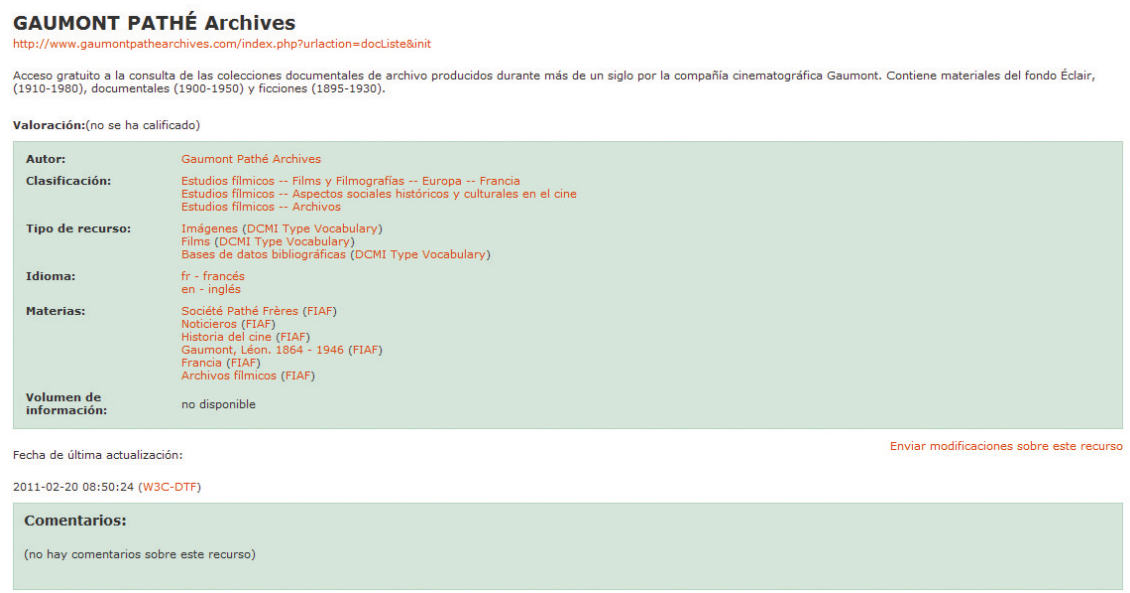

También se muestra el tiempo de recuperación y la posibilidad de ordenación por diferentes campos mediante un filtro de orden alfabético (A-Z/Z-A) o por relevancia, determinada por una combinación de frecuencia y peso del término en la consulta en los campos: título, autor, editor, clasificación, materia, des- 
cripción y URL. A la hora de mostrar los resultados, los campos título, autor, editor, colaborador, clasificación y materia, se presentan como hipertexto, lo que permite ampliar o replantear las búsquedas realizadas.

Por otra parte, los usuarios disponen en todo momento de un área de ayuda para desarrollar los procesos de búsqueda y de exploración, así como de los contenidos y funcionalidades del directorio y uso correcto de la aplicación. También existen mecanismos de feedback y de información con el usuario, ofreciéndole la opción de sugerir bases de datos, enviar comentarios y notificar erratas o errores por medio de formularios.

\subsection{Tipología y ejemplos de contenidos y consultas}

Entre la gama de documentos a consultar en las bases de datos se encuentran filmografías, bibliografías, fotografías, documentos de archivos personales de directores y productoras, ilustraciones, carteles, noticieros, programas de radio y televisión, anuncios, video arte, bancos de metraje - footage-, cortometrajes y films de todas las épocas. Entre las bases de datos incluidas se pueden consultar bancos de imágenes, multibuscadores o multibancos de imágenes y repositorios de documentos textuales y audiovisuales que ofrecen tanto la localización original del documento, como la reproducción digitalizada del mismo o el visionado en formato de video comprimido de films.

Para el contexto que aborda el presente artículo, examinaremos a modo de ejemplo, algunas consultas representativas, ya que una casuística completa excedería el propósito y extensión del mismo.

Pregunta: ¿Que festivales de cine se desarrollarán en septiembre en Polonia? Respuesta: Clasificación temática - Estudios fílmicos -Festivales, premios, eventos y conferencias.

Recurso: Directory of International Film and Video Festivals. [http://film. britishcouncil.org/festivals-directory].

Autor: British Council Film Department.

Descripción: Directorio de festivales de cine, vídeo y televisión de todo el mundo.

Pregunta: Queremos realizar una bibliografía de artículos publicados en revistas especializadas sobre cine y televisión desde 1980 a 1982.

Respuesta: Clasificación temática - Estudios fílmicos - Publicaciones periódicas.

Recurso: Film Literature Index (FLI) [http://webapp1.dlib.indiana.edu/fli/ index.jsp].

Autor: Indiana University. The Trustees.

Descripción: Base de datos bibliográfica de artículos sobre cine extraídos de revistas especializadas de más de 30 países. No da acceso directo al texto completo de los mismos. 
Pregunta: Necesitamos información sobre películas realizadas en Suecia en el año 1999.

Respuesta: Clasificación temática - Estudios fílmicos - Films y Filmografías - Euopa - Suecia.

Recurso: Svenska Filminstitutets filmdatabas [http://www.sfi.se/en-GB/ Swedish-film-database/].

Autor: Svenska Filminstitutet.

Descripción: Base de datos con información sobre cine sueco desde 1897. Contiene cortos, documentales y películas de televisión y material restaurado por la Filmarkivet de Grängesberg.

Pregunta: Queremos localizar documentos digitalizados sobre la historia del cine en los Estados Unidos hasta el presente.

Respuesta: Clasificación temática - Estudios fílmicos - Films y Filmografías - América - Estados Unidos.

Recurso: CineFiles [http://cinefiles.bampfa.berkeley.edu/cinefiles/].

Autor: University of California, Berkeley Art Museum and Pacific Film Archive (BAM/PFA).

Descripción: Base de datos de imágenes de revistas, prensa, festivales y otros documentos de la colección de la Biblioteca del PFA que cubre la historia del cine. También incluye documentos sobre películas de más de 150 directores internacionales y materiales sobre cine mudo americano y soviético.

Figura 4: Imagen de un registro de la base de datos CineFiles con el anuncio de la promoción en prensa de la película The birth of a nation, de D. W. Griffith (2 de noviembre de 1915).

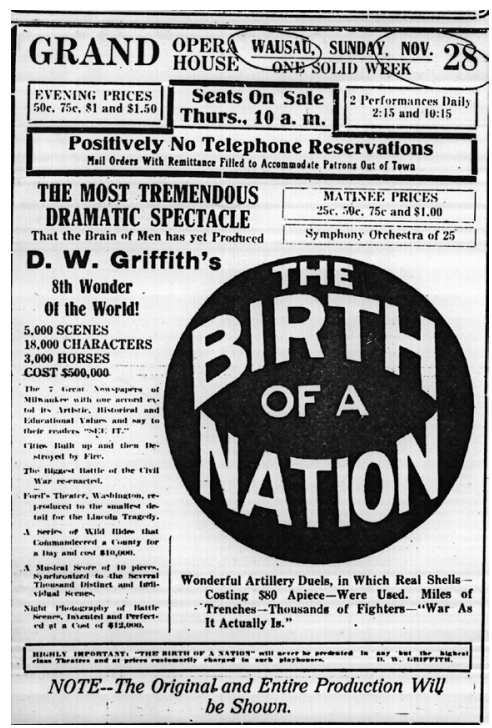


Pregunta: Queremos localizar información sobre la restauración de películas europeas y visualizarlas posteriormente.

Respuesta: Clasificación temática - Estudios fílmicos - Conservación y preservación; Estudios fílmicos - Imágenes y audiovisuales; Estudios fílmicos - Films y Filmografías - Europa; Estudios fílmicos - Archivos.

Recurso: Europa Film Treasures, [http://www.europafilmtreasures.es].

Autor: Lobster Films y Enki Technologies.

Descripción: Base de datos de fondos de archivos cinematográficos, películas restauradas y fichas descriptivas de las filmotecas europeas. Se puede buscar por película, periodo, nacionalidad, filmoteca, género, realizador y actor o actriz.

Pregunta: Queremos conocer las características de locales en Logroño para organizar un festival de cortos.

Respuesta: Clasificación temática - Estudios fílmicos - Salas de Cine; Estudios fílmicos - Industria cinematográfica.

Recurso: MIREM Mapa Informatizado de Recintos Escénicos de España [http://www.mirem.net/].

Autor: Sociedad General de Autores y Editores SGAE y Fundación Autor. Descripción: Base de datos de recintos escénicos de España dedicados a la exhibición de espectáculos musicales, teatrales, coreográficos, cinematográficos y audiovisuales. Contiene datos de los estándares de equipamiento de las salas y del edificio, equipamiento escénico, planos de la sala y del interior del recinto, fotografías de la fachada, de la sala y del escenario. MIREM es un servicio dirigido especialmente a usuarios del sector público y privado del espectáculo, gestores culturales, compañías artísticas, productores, distribuidores y empresas de artes escénicas y centros de información y documentación relacionados con el sector.

Respecto al volumen de información que contiene, a fecha de la redacción de este trabajo (junio de 2012), comunicacioninvisible.net clasifica y describe 285 bases de datos pertenecientes a 42 países. Principalmente son recursos realizados por instituciones, empresas y profesionales de reconocido prestigio. De éstas, únicamente proporciona información completa sobre sus fondos el $35 \%$. El número total de registros que contienen es de 104.410.479, es decir, una media aproximada de 366.000 registros por base de datos, donde la mayoría proporcionan la referencia del documento y solo un $15 \%$ proporciona el documento o texto completo.

La web comunicacioninvisible.net es un servicio gratuito desde sus orígenes y no ha utilizado ningún recurso publicitario. La promoción del mismo se ha materializado mediante el efecto recomendación entre los propios usuarios y por la difusión gratuita de medios de comunicación, revistas especializadas, universidades, congresos, instituciones académicas, comunidades virtuales y profesionales de la información y comunicación. 


\section{Estadísticas de usuarios (datos enero - junio 2012)}

Para finalizar se muestra un resumen sobre los hábitos y tecnologías más utilizadas por los usuarios en la consulta de comunicacióninvisible.net.

- Perfil predominante y procedencia: Usuarios que conocen y manejan información almacenada en bases de datos preferentemente de entornos académicos. El 71,23\% de las visitas se debe principalmente al tráfico redireccionado por enlaces desde otros sitios web, en su mayor parte accede desde bibliotecas y campus virtuales de enseñanza superior. El 24,64 lo consulta conducido por buscadores como Google y el resto directamente desde sus marcadores.

- Procedencia geográfica: España 39,32\%, México 15,52\%, Argentina 8,42\%, Colombia 6,74\%, Reino Unido 5,80\%, Chile 3,16\%, Perú 2,94\%, Venezuela, 2,78\%, Francia 1,55\%, Estados Unidos 1,51\%.

- $\quad$ Visitas: Media mensual de 2.820.

- Tiempo medio de conexión: El 57,81\% de las visitas están conectadas entre 2 y 3 minutos y más de un 10,50 \% permanece en la web entre 4 y 10 minutos.

- Uso: el promedio de páginas consultadas por visita es de 3,31.

- Sistemas operativos más utilizados: Windows 88,15\%, Linux 4,92\%, Macintosh 4,34\%, iPad 0,69\%, Android 0,60\%, iPhone 0,38\%, BlackBerry $0,16 \%$, iPod $0,16 \%$.

- Navegadores más utilizados por los usuarios: Firefox 34,37\%, Chrome 32,23\%, Internet Explorer 27,09\%, Safari 4,20\%, Opera 0,97\%, Android Browser 0,46\%, Opera Mini 0,25\%.

- Sistemas operativos más utilizados en la consultas mediante dispositivos móviles: iPad 30,52\%, Android 26,51\%, iPhone 16,87\%, BlackBerry 7,23\%, iPod 7,23\%, SymbianOS 2,01\%.

- Dispositivos móviles más utilizados: Apple iPad, Apple iPhone, Apple iPod Touch, HTC Magic, Acer A500 Picasso, Nokia N8-00 N8, RIM BlackBerry 9700 Bold, Samsung GT-I9000 Galaxy S, Samsung GT-P7300, Galaxy Tab 8.9 .

- Buscadores más utilizados en la localización del DTE: Google 84,56\%, Bing 9,40\%, Yahoo 3,69\%, Search.com 2,01\% y Ask 0,34\%.

- Consultas: El 15\% de los usuarios consultan el servicio navegando mediante la opción clasificación temática, un $51 \%$ por el formulario de búsqueda sencilla y el resto por el formulario de búsqueda avanzada. 


\section{Consideraciones finales}

La principal revolución que ha proporcionado el acceso a las bases de datos, repositorios y bancos de imágenes de libre acceso en Internet, ha sido poner a disposición una amplia gama de objetos como textos, documentos de archivo, fotografías, pinturas, dibujos, objetos de museo, sonidos, música, emisiones de radio, vídeos, películas, noticieros, programas de TV, etc., con un proceso de exploración más activo basado en sistemas expertos que aportan consistencia, fiabilidad y menos ambigüedad a la hora de recuperar información.

Esto ha supuesto por una parte, el aumento de la rapidez en la consulta del patrimonio audiovisual y su mejor conservación, preservación y democratización y por otra, la necesidad de crear aplicaciones cada vez más potentes capaces de gestionar esta información en tiempo real, pero sobre todo la mejora de las posibilidades de formación en este campo de conocimiento.

Pero para su descubrimiento, como propone Lewandowski (2008: 936) deben trabajar todos los protagonistas. Desde el punto de vista comercial, los motores de búsqueda han de potenciar medidas de cálculo y financieras necesarias para la construcción de índices apropiados. Y desde las organizaciones que tienen la experiencia en la recuperación de información en Internet, continuar con la labor de realizar tesauros, clasificaciones y vocabularios controlados que ayuden a normalizar la terminología y descripción de contenidos.

Este directorio nace con la premisa de ser, en la medida de lo posible, una fuente de información estructurada que ayude a buscar, localizar e identificar una porción de información existente en Internet.

\section{Bibliografía}

Bergman, Michael K. (2001). The Deep Web: Surfacing Hidden Value. En: The Journal of Electronic Publishing (JEP), v. 7, nº 1.

Codina, Lluís (2001). Evaluación Bases de datos documentales y Motores de Búsqueda. Parámetros e indicadores. Disponible en: http://www.lluiscodina. com/evalbd.doc. Consultado el 20/06/2012.

Cuadra Colmenares, Elena de la (2006). Documentación cinematográfica digital: el gestor digital. En: Documentación de las Ciencias de la Información, $\mathrm{n}^{0}{ }_{29}$, 165-205.

FIAF (2010). International Index to Film Periodicals. General Subject Headings. Disponible en: http://www.fiafnet.org/content/Film\%20General\%20Subjects. doc. Consultado el 18/06/2012.

Howarth, Lynne C. (2003). Modelos de Metadatos para Pasarelas Temáticas. En: 69th IFLA General Conference and Council, 1-9 de agosto. Berlin. Disponi- 
ble en: http://www.ifla.org/IV/ifla69/papers/053s_trans-Howarth.pdf. Consultado el 03/06/2012.

Lewandowski, Dirk; Mayr, Philipp (2006). Exploring the Academic Invisible Web. En: Library Hi Tech, v. 24, ${ }^{0}$ 4, 529-539.

Lewandowski, Dirk (2008). The Retrieval Effectiveness of Web Search Engines: Considering Results Descriptions. En: The Journal of Documentation, v. 64, $\mathrm{n}^{\mathrm{o}}$ 6, 915-937.

López de Solís, Iris (2007). Nuevos perfiles profesionales en el mundo de la documentación audiovisual: el researcher". En: IX Jornadas de Gestión de la Información. 22 y 23 de noviembre. Madrid.

Lynch, P., Horton, S. (2009). Web stile guide: basic design principles for creating web sites. 3 ed. New Haven: Yale University Press.

Tramullas Saz, Jesús; Garrido Picazo, Piedad; Navarro Bonilla, Diego; Senso Ruiz, José Antonio (2003). Planificación y evaluación de directorios científicos especializados para Internet: su aplicación como instrumentos de docencia en sistemas de enseñanza y aprendizaje virtual. Informe del Programa de Estudios y Análisis, Proyecto EA2003-0052”. España. Ministerio de Educación y Ciencia.

Worsfold, Emma (1998). Subject gateways - fulfilling the DESIRE for knowledge. En: Computer Networks and ISDN Systems archive, v. 30, n ${ }^{\circ} 16-18,1479-1489$.

\section{Referencia de este artículo}

Albiñana Bertomeu, Ricardo (2012). Un directorio especializado sobre estudios fílmicos. En: adComunica. Revista Científica de Estrategias, Tendencias e Innovación en Comunicación, $\mathrm{n}^{\circ} 4$. Castellón: Asociación para el Desarrollo de la Comunicación adComunica, Universidad Complutense de Madrid y Universitat Jaume I, 199-215. DOI: http://dx.doi.org/10.6035/2174-0992.2012.4.12 